\title{
EL PROYECTO TERRITORIAL DEL BALNEARIO URUGUAYO Modelos, paradigmas y utopías
}

\author{
Eleonora Leicht \\ Arquitecta, Magister en Diseño Urbano, Oxford Brookes University \\ Docente e investigadora de la Facultad de Arquitectura, Universidad de la República
}

\section{RESUMEN}

Ante las transformaciones territoriales aceleradas que se producen en la región costera Sur del Uruguay, se indaga acerca de su proceso de urbanización en clave multiescalar, donde la conformación de los balnearios juega un rol destacado. Por un lado se explora el surgimiento y desarrollo del balneario a principios del siglo $\mathrm{XX}$ como un paisaje cultural específico, testimonio de un cambio de paradigma en los hábitos de la sociedad rioplatense. Por otro, se aborda a una escala regional el proyecto territorial, utópico e inacabado, implícito o explícito en el proceso de génesis de los balnearios. Se pone en consideración la influencia de la presencia cercana, al otro lado del Río de la Plata, de la región metropolitana de Buenos Aires, con 15 millones de habitantes. La puesta en valor de la cultura e identidad de los balnearios resulta fundamental para que continúen siendo entornos vitales. A la presencia del balneario como paisaje cultural, se contraponen iniciativas emergentes de nuevos modelos de habitar y de vivir el tiempo libre, los llamados clubes de campo.

Palabras clave: paisaje cultural, balnearios, proyecto territorial, turismo y patrimonio 
ID_INVESTIGACIONES

\section{ABSTRACT}

Regarding the accelerated transformations that the Coastal South Region of Uruguay is undergoing, the article explores its anthropization process in a multiescalar approach, where the shaping of the seaside resorts has played a leading role. On one hand, the outcome and development of the seaside resort at the beginning of the XX century is analysed as a specific cultural landscape, proof of a paradigm change in the local society. On the other hand, the regional land project that is beneath the process of shaping the seaside resort is explored, utopic and unfinished, implicit and explicit. It is evaluated the presence of 15 million people at the other side of the River Plate, in the metropolitan region of Buenos Aires. The highlight of the seaside resort as a cultural landscape, is opposed to the outcome of an emerging lush way of living the spare time: the so called countries or gated communities

Key words: cultural landscape, Seaside resorts, Land Planning, Tourism and Heritage 
ID_INVESTIGACIONES

\section{DINÁMICAS ACELERADAS DE TRANSFORMACIÓN DEL PAISAJE}

En la faja de la Costa Sur $^{1}$ del Uruguay se observan dinámicas de transformación acelerada, acentuadas probablemente en los últimos seis años debido al período de bonanza económica que el Uruguay y los países vecinos están atravesando. Desarrollos inmobiliarios costeros de diversas formas son el común denominador, desde Colonia de Sacramento y Carmelo hasta las lagunas de Rocha. En un marco de políticas públicas de fomento al turismo, dada la cantidad de empleo que genera e incluyendo la industria de la construcción, es difícil plantear miradas críticas ante tales iniciativas.

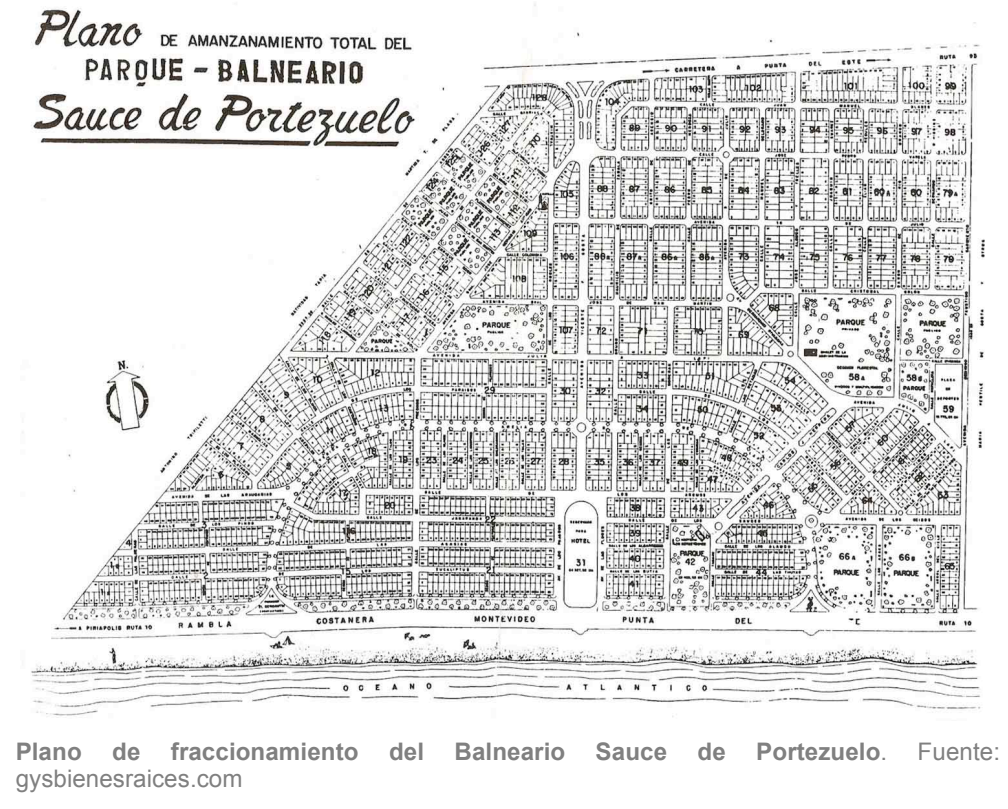

${ }^{1}$ Se denomina Costa Sur a la región del Uruguay que abarca desde Punta Gorda en el Departamento de Colonia al Oeste, hasta el Arroyo Chuy en el Departamento de Rocha al Este, frontera con Brasil 


\section{ID_INVESTIGACIONES}

Estos emprendimientos aterrizan en las oficinas departamentales de planificación territorial, y ante la ausencia en la mayoría de los casos de un modelo territorial guía, son autorizados alegando razones de corto plazo. En caso de existir dicho marco planificador, no propone instrumentos de gestión que permitan una política de negociación ágil con la iniciativa privada.

Basta detenerse en el departamento de Maldonado, el más transformado en los últimos años, donde se desarrolla el segundo polo metropolitano luego de Montevideo, el aglomerado urbano Punta del Este-Maldonado-San Carlos, con 110.000 habitantes en el año 2004, población a la que se suman 160.000 más en temporada de verano (Acuña et al., 2010). La génesis de este polo es de una cualidad bien distinta a la de Montevideo, ya que surge como demanda de la actividad económica principal de la región, que es el turismo. Gran parte de la población radicada en forma permanente es producto de la migración interna, que ha venido atraída por las fuentes de trabajo derivadas del turismo, tales como la construcción y prestación de servicios.

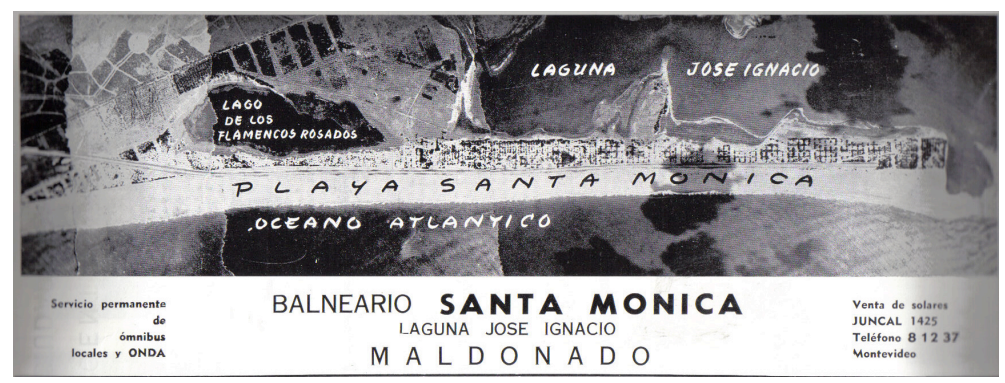

Publicidad del fraccionamiento del Balneario Santa Mónica, en "Maldonado en su Bicentenario", 1957 


\section{ID_INVESTIGACIONES}

Paradójicamente, lejos del supuesto bienestar que podría esperarse para esta población, se constatan fenómenos de fragmentación y segmentación social, con aumento de asentamientos irregulares y la consiguiente extensión de la mancha urbana. En paralelo se observa un preocupante vaciamiento de las áreas centrales de las principales localidades que integran el conglomerado.

Como remate, nuevas presiones sobre el territorio rural costero emergen de selectos productos inmobiliarios, sin un arraigo de desarrollo local, como son los clubes de campo y las chacras marítimas, sustituyendo en ocasiones a la actividad agropecuaria tradicional. Esta modalidad constituye una nueva forma de concebir el tiempo libre, con mucha influencia de la proliferación de barrios cerrados en Buenos Aires a partir de los años 80. El club de campo estacional, para temporada o fin de semana, se manifiesta con particular énfasis en el departamento de Maldonado, más que en cualquier otra región de Uruguay.

La desigual distribución de la riqueza configura dos escenarios: por un lado el crecimiento de asentamientos surgidos por la necesidad de vivienda propia, ubicados en zonas precarias, de riesgo ambiental o sin las infraestructuras necesarias. En contrapartida, algunos sectores de más altos ingresos -la mayoría turistas extranjeros- optan por enclaves de veraneo cerrados, que segmentan e inhabilitan la accesibilidad al territorio, imponiendo la necesidad de repensar las estrategias de integración.

Como contrapunto a esta tendencia emergente, que de continuar no haría más aumentar las desigualdades territoriales en la región, es necesaria una visión de un modelo territorial integrador que considere asuntos clave como el paisaje cultural, la identidad y el patrimonio. Se propone una mirada al paisaje como principal recurso del turismo, a la vez que se explora el balneario como un paisaje cultural específico a poner en valor, rescatando su patrimonio construido a la vez que los imaginarios, modelos y paradigmas que subyacen en su devenir. 
ID_INVESTIGACIONES

\section{LAS DOS ORILLAS: EL RÍO DE LA PLATA COMO TERRITORIO}

El nacimiento del balneario se explica como la contracara del crecimiento de la de la metrópolis contemporánea. Surge como descompresión y válvula de escape de la vida asfixiante de la ciudad para una élite.

La dimensión del balneario uruguayo no se explica como desahogo únicamente de la metrópolis montevideana y otras ciudades uruguayas, sino que involucra a Buenos Aires, al otro lado del río, y solamente a 50 kilómetros de nuestra costa, que a principios del siglo XX ya contaba con más de un millón y medio de habitantes (1.575.814 habitantes. Tercer Censo Nacional Argentino, 1914).

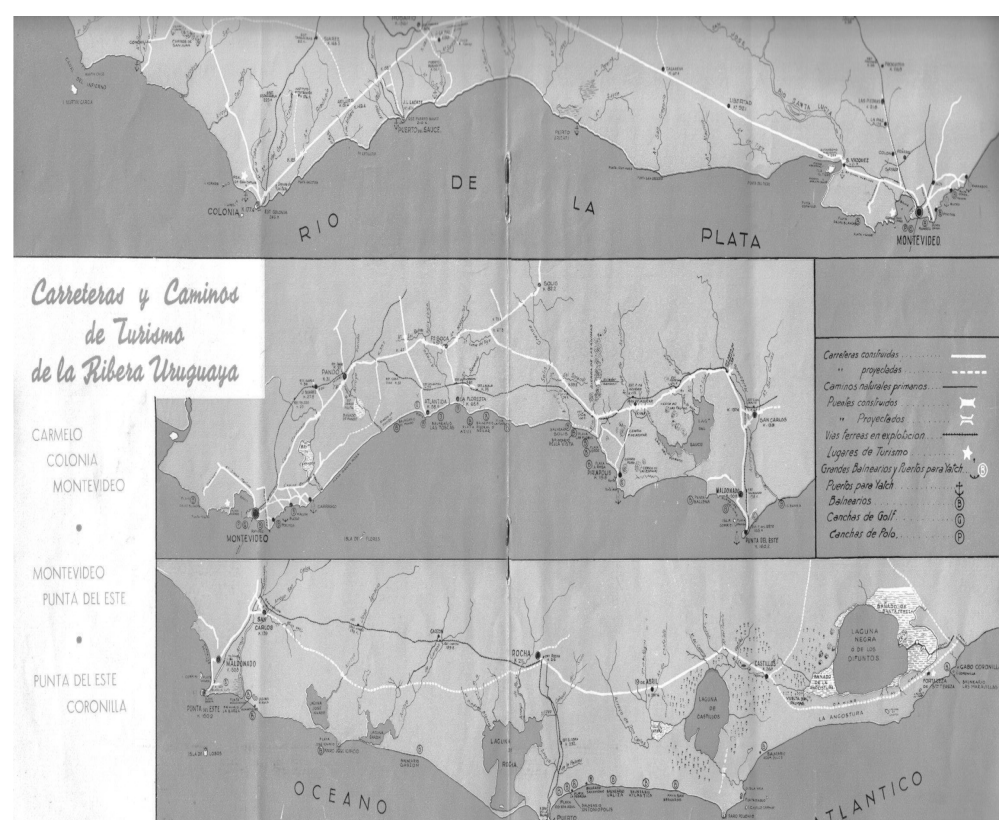

"La ribera uruguaya" folleto de la Comisión Nacional de Turismo, S/F 


\section{ID_INVESTIGACIONES}

Colonia es, por cercanía, el territorio donde esa influencia es más notoria. En efecto, se ha caracterizado como una región en situación de frontera, donde aún sin haber contacto territorial, sus habitantes deben adaptarse o rechazar los cambios materiales y culturales que llegan desde la otra orilla, junto con turistas y nuevos residentes.

A nivel físico-espacial, y desde una perspectiva histórica, el territorio de Colonia contiene hoy huellas que denotan una influencia de Buenos Aires de larga data. Piénsese en las caleras y areneras en torno a los puertos de Conchillas o Bocas del Rosario, que constituyeron un recurso fundamental para la construcción de la ciudad y su puerto. Asimismo, los Hoteles en Colonia Suiza, establecidos a fines del siglo XIX, o la Estancia de Anchorena, son algunos de los testigos que hablan de esa suerte de refugio que estos recintos constituyeron como lugar de descanso favorito y huída del mundanal ruido de las clases altas porteñas.

La abundante comunicación mediática, sumada a las conexiones diarias a través del Puerto de Colonia y de Carmelo, verdaderos puentes fluviales que unen ambas orillas en una hora, acercan potencialmente al territorio uruguayo una población de 15 millones de habitantes correspondientes al Área Metropolitana de Buenos Aires. La influencia que ejerce dicha ciudad, trascendiendo límites naturales y políticos, se manifiesta de manera diversa y ya ha sido objeto de estudio desde distintas miradas disciplinares.

Algunos autores (Sprechmann et al., 2006) mencionan una creciente influencia metapolitana de Buenos Aires a lo largo de la Costa Sur del Uruguay donde se señala a Colonia como portal de entrada a una vasta área, de límites imprecisos, que alcanza a Maldonado y Rocha. 
ID_INVESTIGACIONES

Esta Región Urbana de la Costa Sur del Uruguay se vería expandida de concretarse algunos emprendimientos de integración macrorregional anunciados como el Eje Vial, la construcción del Puente en Laguna Garzón y el puerto de aguas profundas en La Paloma.

Por otra parte, la consideración de ambos márgenes del territorio platenseoceánico- desde una mirada sistémica, no ha sido la tónica conceptual en estudios urbanos anteriores. Por tanto se subraya la pertinencia de considerar a dicho territorio como una gran pieza ambiental sudamericana (Borthagaray, 2002) a cuidar y poner en valor, compartiendo responsabilidades y beneficios.

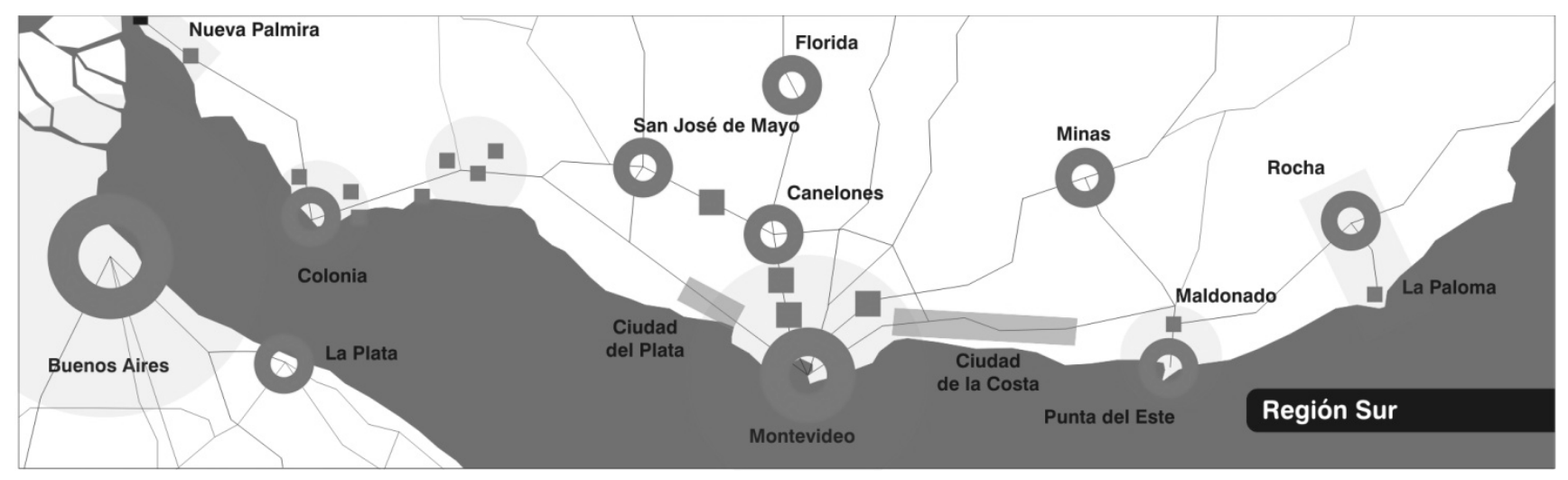

Costa Sur de Uruguay. Fuente: Intendencia de Montevideo. Revisión del Plan de Ordenamiento Territorial. Documento de avance, 2010 
ID_INVESTIGACIONES

\section{EL PROYECTO TERRITORIAL COSTERO: DISCURSO Y EJECUCIÓN}

Como herederos de un territorio al que se pretende proyectar, se examina el proyecto territorial costero y su forma, implícito en el proceso de génesis de los balnearios. Nunca hubo un "gran proyecto" o modelo territorial que abarcara toda la costa, sino que diversas políticas sectoriales fueron dejando su huella, obviamente muchas veces desencontradas o no concluidas. Se revisan las lógicas y políticas públicas y para ello se revisan los intentos planificadores desde el Estado a través de normativas como la Ley de Centros Poblados, el Código de Aguas o la más reciente Ley de Ordenamiento Territorial.

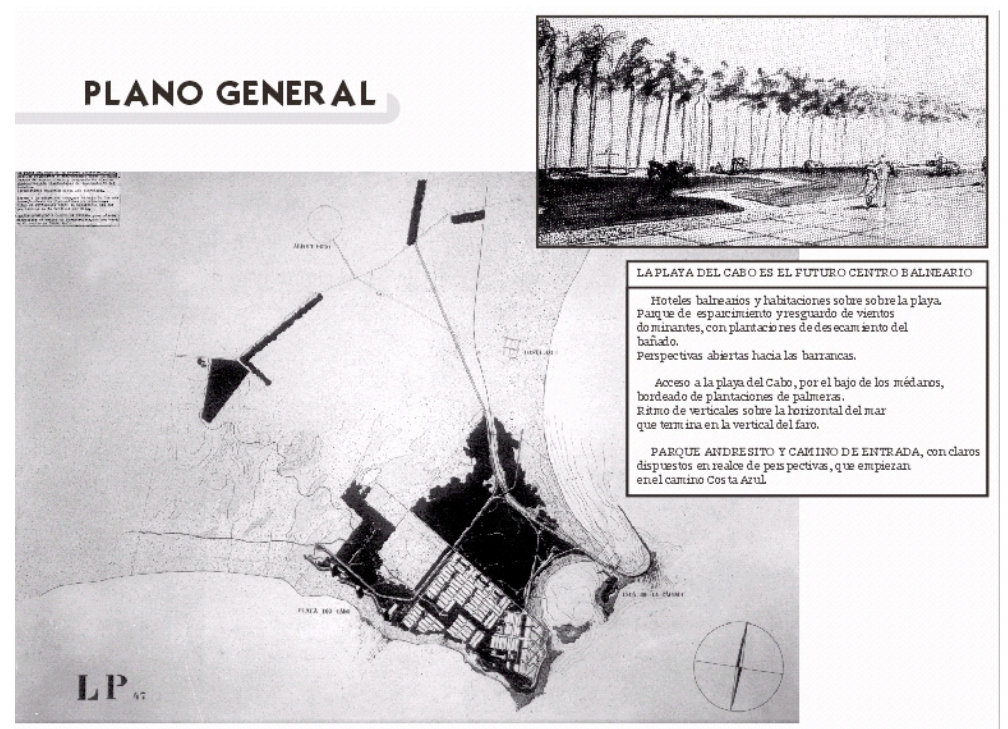

Proyecto para la ampliación del Balneario La Paloma, Rocha, Arquitecto Gómez Gavazzo. Archivo Francisco Nogueira, ITU, 2002 


\section{ID_INVESTIGACIONES}

A partir de 1930 el Estado impulsó el turismo como actividad económica alternativa. En ese marco, en 1935 se crea la Dirección Nacional de Turismo que juega un rol importante de difusión nacional e internacional de lugares turísticos, entre ellos la Costa Sur y sus balnearios, a través de una revista con tirada regular y folletería. La imagen, más que el texto, es lo que predomina en dichas publicaciones. Primero se hace mayor énfasis en posicionar Montevideo, luego se promocionan los demás balnearios de la Costa Sur.

Asimismo se impone cruzar paradigmas y sensibilidades de origen diverso que van construyendo el paisaje costero y del balneario. Para comprender más ampliamente el fenómeno, conviene recordar el poder del discurso médico dominante en la sociedad del 1900, con sus recomendaciones de tomar baños de sol, mar y aire puro para la cura de muchas dolencias.

También influye el entusiasmo y la confianza de la élite profesional en las transformaciones técnicas del territorio enmarcadas en el paradigma de progreso y desarrollo nacional. El ingeniero con la construcción de carreteras, represas y puertos, el agrimensor y el rematador en su afán de fraccionar $y$ forestar, el arquitecto incursionando en nuevas espacialidades y formas a escala urbana y arquitectónica.

El balneario se transforma en una utopía que admite varias lecturas: para algunos la utopía de la felicidad concretando el sueño de la casa de fin de semana, para otros la posibilidad de ensayar sin prejuicios los lenguajes modernistas que comenzaban a difundirse a través de las revistas de arquitectura europeas, o con la venida al Río de la Plata de visitantes ilustres, como Le Corbusier en 1929. 


\section{ID_INVESTIGACIONES}

En Uruguay la mutación del gusto empieza en Montevideo. Si bien la ciudad le da la espalda a la costa desde su fundación como ciudad mediterránea, a fines del siglo XIX el mar empieza a adquirir un rol significativo para los montevideanos como espacio higiénico y recreativo. Las playas Capurro y Ramírez son concebidas como balnearios en la segunda mitad del siglo XIX, asociado con la instalación de la compañía de tranvías. Luego le siguen Pocitos y Carrasco. La construcción de la Rambla Sur marca un hito que transformó la costa céntrica en paseo emblemático. Montevideo ciudad balnearia tuvo su auge a mediados del siglo XX, pero en los 70 la situación se torna insostenible por el grado de contaminación de las aguas para baños. El Plan de Saneamiento Urbano, concebido en los 70 y concretado a partir de los 80 , logra revertir la situación y recuperar la calidad del agua para baños de las playas, proceso que continúa hasta el presente. En efecto, el Plan de Saneamiento IV, que implica la construcción de un emisor final en Punta Yeguas tiene entre sus objetivos principales preservar la calidad ambiental de las playas de la Costa Oeste.

El desarrollo de la ruta costera número 10 , construida en la primera mitad del siglo pasado es concebida en el marco de un ambicioso proyecto territorial que pretendía abarcar la costa sur del país, desde Montevideo hasta Rocha. Dicho proyecto tiene su correlato en la propuesta del arquitecto Mauricio Cravotto, quien, muy atento al crecimiento poblacional que Montevideo experimentaba en la década del '30, avizora su expansión hacia el este como una sucesión de balnearios ubicados en la faja costera, articulados por un "park-way atlántico" o ruta forestada a lo largo de la costa que aportaría, además de la necesaria conectividad, paisajes variados y atractivos.

Sin embargo, la materialización de la ruta 10 fue lenta y fragmentada, debido a que su trazado se iba encontrando con accidentes geográficos, tales como dunas y lagunas, que hicieron difícil y costosa su ejecución. 
Es interesante comparar la transformación territorial del departamento de Canelones con el de Maldonado, ante la avanzada del turismo costero. En Canelones, la Ruta Interbalnearia no presentó mayores dificultades en cuanto a su materialización, y su trazado, a una distancia de 1 kilómetro promedio del cordón dunar, promovió un continuum de balnearios que se conoce hoy en día como Ciudad de la Costa. A partir de los años '70 la vivienda de temporada en Canelones se transforma paulatinamente en vivienda permanente para buena parte de los montevideanos, ya sea como elección o como única alternativa. La Avenida Giannattasio, eje vertebrador de dichos fraccionamientos, se convierte así en la extensa y caótica vía lineal comercial que hoy conocemos. Al presente la Ciudad de la Costa constituye una verdadera ciudad-borde o cinta urbana paralela al mar, con 17 kilómetros de longitud y 3 kilómetros de ancho. Dicha ciudad actualmente cuenta con una población que supera los cien mil habitantes. Ya luego del Arroyo Solís Chico, los balnearios se suceden con mayor intermitencia.

En cambio, en el Departamento de Maldonado, se constata un desarrollo costero vinculado a una primaria infraestructura vial desarrollada en sistema de peine, donde el eje principal es la Ruta 9, ubicada a considerable distancia de la costa, desde la cual se accede a través de caminos transversales a los distintos parajes balnearios. El sistema ferroviario responde a una lógica similar. Así era el esquema de accesibilidad hasta los años cincuenta, lo que promueve el desarrollo balneario de manera fragmentada. Gracias a esta modalidad de accesibilidad, la costa no se urbaniza en toda su extensión, sino que lo hace a través de enclaves balnearios, mojones urbanos que alternan con tramos de costa de alta naturalidad. Piriápolis, Punta del Este, La BarraManantiales, José Ignacio. A cada uno de ellos se accedía exclusivamente por un camino transversal a la Ruta 9, no era posible recorrerlos por la costa, salvo a caballo o jeeps por la playa. En realidad esta alta naturalidad en los tramos

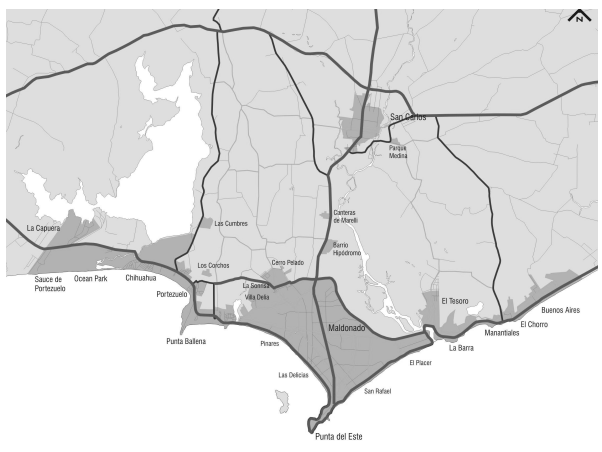

Sistema de peine: Propuesta de jerarquización vial para el Plan Local de Maldonado-San Carlos-Punta del Este. Fuente: Plan Local para la Aglomeración Central, ITU, 2010 
intermedios es en muchos casos solo una apariencia, ya que el terreno ya está fraccionado y loteado como urbano, aun sin contar con la infraestructura mínima necesaria.

Es el caso de fraccionamientos balnearios tales como balneario Buenos Aires o Eden Rock, realizados antes de la aprobación de Ley de Centros Poblados de 1946. Estos balnearios, si bien fraccionados hace más de 60 años, han tenido un completamiento discreto, quedando los parques, hoteles y ramblas costaneras previstas solo en los planos. No obstante el balneario Buenos Aires ha tenido un crecimiento importante en los últimos diez años, con la construcción de infraestructura que mejoró su accesibilidad, tal como el puente sobre el arroyo Maldonado de los 70 , y el puente sobre la laguna José Ignacio en los 80 , sumado a la expectativa de la construcción del puente sobre la laguna Garzón. Muchos propietarios de terrenos descubren que su lote coincide con el curso de una cañada, fruto de fraccionamientos poco escrupulosos. De los 122 kilómetros de costa de Maldonado, solo quedan unos tres kilómetros cuyos suelos adyacentes están categorizados como rural, el cual se ubica inmediatamente al Este de Punta Negra, casualmente donde la Ruta 10 deja de ser costera.

Continuando con el tramo de Rocha, donde balnearios con diversa identidad y jerarquía como La Paloma, La Pedrera, Balizas, Aguas Dulces, La Coronilla, alternan con zonas de alta naturalidad en apariencia, pero que también fueron fraccionadas a mediados del siglo XX. Son los llamados balnearios fantasmas; en el tramo de La Paloma a Cabo Polonio, de 11 kilómetros, hay nueve de este tipo. Los propietarios de los loteos, muchos argentinos, se han desentendido de los mismos. Es un territorio "congelado" hace 60 años, sin un destino claro.

La matriz ambiental de la región rochense es de especial interés. Cuenta con la presencia de la costa oceánica y una cadena de lagunas que se extiende hasta el sur de Brasil, con presencia de marismas que propician una fauna y una flora

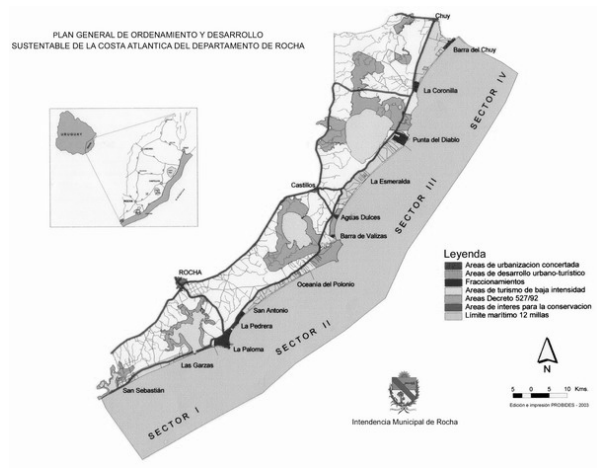

Faja costera del departamento de Rocha. Fuente: Ordenanza Costera de Rocha, IR, 2001 


\section{ID_INVESTIGACIONES}

únicas en el país. Si bien estos paisajes aún están en buena medida inalterados, los efectos negativos de la antropización ya se hacen sentir, especialmente en las lagunas de Rocha, y Garzón. Los proyectos de construcción de un puerto de aguas profundas en La Paloma y de un debatido puente en la Ruta 10 sobre la laguna Garzón, suponen estructuras de alto impacto que, de ejecutarse, cambiarán para siempre el carácter de esta región. La especulación salvaje sobre el precio de la tierra no se ha hecho esperar, como revela el caso del fraccionamiento Las Garzas. La construcción del canal Andreoni en los años 70 tuvo un efecto perjudicial para las dinámicas costeras. Prueba evidente de ello son las estructuras hoteleras abandonadas en el Balneario La Coronilla, donde la contaminación de la playa provocó la deserción del turismo.

Las ciudades costeras atlánticas están fuertemente marcadas por la estacionalidad. Paradójicamente, el capital natural que motiva la localización de importantes zonas balnearias en esta región del país es depredado por el turismo masivo.

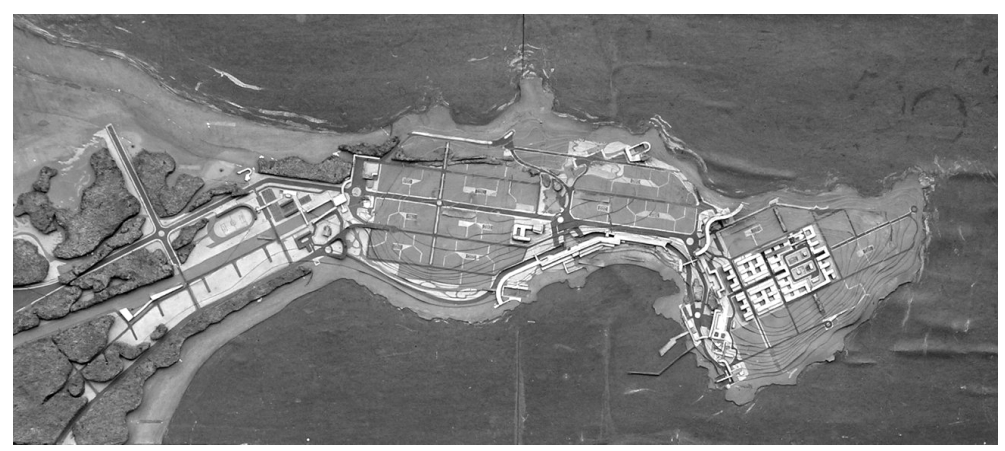

Plan para la península de Punta del Este. Arquitecto Gómez Gavazzo, 1935. Maqueta del Instituto de Teoría de la Arquitectura y Urbanismo, Facultad de Arquitectura 


\section{EL BALNEARIO COMO PAISAJE CULTURAL ESPECÍFICO}

Si se define paisaje cultural como un ámbito geográfico asociado a un evento, una actividad o a un personaje histórico y que contiene, por tanto, valores estéticos y culturales 2, entonces el balneario constituye un tema muy pertinente de abordar desde esta óptica. En efecto el balneario es un ámbito geográfico sin lugar a dudas bien específico caracterizado por ser un territorio urbano adyacente al mar con población intermitente. Pero esta condición, si bien necesaria, no es suficiente para definirlo. El balneario está asociado a la eventualidad de lo estacional, a los flujos signados por las mareas de las temporadas. Está asociado a la actividad turístico-recreativa que suele realizarse en vacaciones y a los equipamientos necesarios para que ello suceda. En la mayoría de los balnearios se pueden identificar personajes históricos que contribuyeron a consolidarlo como tal, o ya son parte de su leyenda. Imposible disociar Francisco Piria de Piriápolis, o a Páez Vilaró de Punta Ballena, a título de ejemplo. Individuo y territorio allí se hacen uno. La puesta en valor de la cultura e identidad de los balnearios resulta fundamental para que continúen siendo entornos vitales.

El balneario es una forma de urbanización específica, diferente a una ciudad corriente. Sus trazados y ramblas, el aporte del verde y el árbol, sus equipamientos, sus imaginarios asociados, conforman un paisaje cultural urbano bi-polar cambiante según la estacionalidad. El invierno bucólico, el bullicio del verano. Es la construcción de una utopía que consiste en alejarse del bullicio de la gran ciudad, que colma los deseos de huir de ella, al decir de Levi-Strauss.

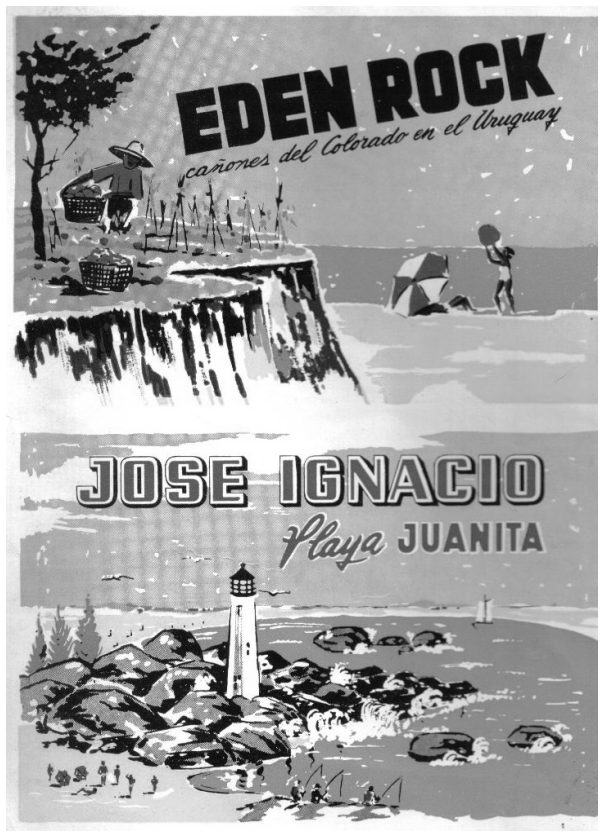

Publicidad en la Revista "Maldonado en su Bicentenario", Intendencia de Maldonado 1957

Balneario

(Del latín: balnearius)

1. adj. Perteneciente o relativo a los baños públicos,

especialmente a los medicinales.

2. $m$. Edificio con baños medicinales y en el cual suele darse hospedaje.

Fuente: Real Academia Española

\footnotetext{
${ }^{2}$ Sabaté, J.: Paisajes culturales. El patrimonio como recurso básico para un nuevo modelo de desarrollo. En Revista Urban no. 9, 2004, p. 8
} 


\section{ID INVESTIGACIONES}

La génesis del balneario uruguayo se remonta a los finales del siglo XIX, cuando comenzaron una sucesión de fraccionamientos para viviendas de veraneo realizados sobre la costa del Río de la Plata, en Montevideo y hacia el Este. La toponimia de los mismos es representativa del nuevo hedonismo reinante: denominaciones tales como El Pinar, El Bosque, Shangrilá, Solymar, Atlántida, La Floresta, etc., evocan la atmósfera que por entonces resultaba atractiva a los potenciales compradores de los fraccionamientos, alejados del mundanal ruido, en una especie de utopía realizable para una élite. La recreación, el ocio y la búsqueda de la salud, antes focalizado en las quintas del Prado u hoteles rurales, empieza a asociarse a los baños de sol y mar. Se genera en torno a la costa y la playa un cambio de sensibilidad: El primordial temor que provocaba el mar y las dunas ingobernables de nuestra costa, se logra revertir a través de la domesticación de la naturaleza, principalmente a través de la forestación masiva, que Jorge Luis Borges dio en llamar la reverencia del árbol en la otra banda haciendo obvia referencia a la Banda Oriental, en contraste con la descampada costa bonaerense. También se procede a la construcción de equipamientos costeros que hicieran más amable la proximidad del mar: las ramblas o paseos marítimos y los hoteles. La costa se toma entonces en consideración como lugar saludable, de recreación y ocio donde recuperar el bienestar.

Ya en 1900, en el Diccionario Geográfico de Orestes Araújo figura el balneario como concepto diverso a la ciudad o el pueblo, como dejan entrever las descripciones de Punta del Este o Piriápolis. La publicación de Araújo fue el fruto del trabajo de varios años por parte de un equipo de expertos liderados por el geógrafo, donde se registran en sus mil páginas más de cinco mil voces de ciudades, pueblos, villas, cerros, arroyos y cañadas, que de no haber sido por el libro se hubieran perdido para siempre.
Piriápolis, balneario de establecimiento de baños situado a orillas del puerto del inglés, sobre una playa amplia y arenosa inmediata a la proyectada ciudad de Piriápolis. Dispone de un hotel de lujo, cómodo y espacioso, con capacidad para 200 personas. Sus alrededores son sumamente pintorescos por la cadena de cerros que en ellos se encuentran, como ser el de los gigantes, el de Pan de azúcar, el de Cristo, el del Toro, el del Medio y el del Inglés, habiendo además multitud de sitios adecuados para paseos y excursiones: bosques, fuentes, granjas, viñedos, canteras, ramblas, etc. Se podría ir a Piriápolis por la vía fluvial, pero la falta de vapores obliga a los viajeros a apelar al ferrocarril de Montevideo a Maldonado, bajando en las Flores o en Pan de Azúcar desde donde el viajero puede trasladarse a Piriápolis en carruaje o en automóvil. Este balneario aventaja a muchos otros de la República en la mayor salsedumbre de sus aguas y en la pureza del aire que en el se respira, cualidades que constituyen su principal mérito.

Fuente: Araújo, O., 1900, p. 374 


\section{ID_INVESTIGACIONES}

Los balnearios poseen formalizaciones diversas que combinan geometrías ortogonales y curvilíneas, buscando una imagen pintoresquista asociado a la idea de la ciudad jardín. En casi todos los casos estos fraccionamientos son acompañados por plantaciones de árboles que, entre otros cometidos, se proponían fijar las dunas que existían en la zona. Todo fraccionamiento venía acompañado de una forestación masiva, atendiendo a temas higiénicos y estéticos. Se creía en los beneficios del recambio de oxígeno que genera la masa arbórea, para el tratamiento de las afecciones respiratorias. También en algunos casos se incorpora la dimensión estética, como es el caso del pionero habitante de Punta Ballena, Francisco Lussich, quien no solo forestó con pinos buena parte de las dunas existentes, sino que creó un arboretum con más de dos mil especies de todo el mundo, único en Latinoamérica. También en Punta Ballena, la familia Previtali, una de las primeras en establecerse allí, colaboró a la generación del paisaje que hoy conocemos en esa zona, con cientos de hectáreas de pinares.

También el territorio virgen es oportunidad de total libertad para innovar y realizar tabula rasa, no había otro palimpsesto que respetar más que el que impone la naturaleza, sin las constricciones creativas que el profesional suele encontrase en la ciudad consolidada. El balneario se puede leer en algunos casos como lugar de ensayo de expresiones tempranas de la modernidad. desde la escala del diseño urbano como el que practica el arquitecto catalán Antonio Bonet en Portezuelo o el arquitecto Carlos Gómez Gavazzo en La Paloma, a concreciones arquitectónicas en lenguajes innovadores vinculados a la modernidad, como los hoteles en los balnearios de Atlántida o La Floresta, en estilo Art Deco, o decididamente modernos como en la hostería La Solana del Mar, también de Bonet.
Punta del Este, el más balneario de los muchos y hermosos balnearios de nuestra región marítimafluvial, es un emporio de arquitectura, de riqueza y de hermosura. Más de 20 millones de pesos están representados ya en los hoteles monumentales y palacios particulares, que se destacan, unos días en el aire diáfano de las mañanas transparentes, otros, en las brumas tenebrosas de las noches que asustan...Punta del Este se puebla y se despuebla como las colmenas, cuando las abejas van a libar. para después elaborar. En verano es una ciudad que reúne varios miles de habitantes, en invierno es una aldea austral.

Fuente: Araújo, O., 1900, p. 383 


\section{ID_INVESTIGACIONES}

Los balnearios marítimos cumplen una función recreativa a la vez que son concebidos como centro de salud, punto de veraneo higiénico, pero también como centro de vida social, articulado principalmente en los lugares de estancia que eran los hoteles. La película Muerte en Venecia de Lucchino Visconti (1971), protagonizada por Dirk Bogarde como huésped sin sosiego del majestuoso Hotel des Bagnes, capta sensiblemente la atmósfera particular de un lugar de veraneo italiano de principios de siglo $\mathrm{XX}$, con sus colores, sus estados de ánimo, sus ritmos y ceremonias. Los hoteles jugaban un papel fundamental para la propia comunidad, que es el de brindar el espacio físico donde una nutrida agenda social tiene lugar, es decir, se presentan en una relación con la comunidad que trasciende el hecho del alojamiento que brindan (Leicht, 2005). En los hoteles se celebraban bodas, carnavales, bailes, banquetes y otros eventos de la comunidad. Por lo tanto debían estar diseñados a tales efectos, dando prioridad a los espacios colectivos: comedores, salas de estar, salón de baile. Para el turista de aquella época era fundamental que el hotel, además de albergarlo, cumpliera la función de casino. No en el sentido más conocido de juegos de azar, sino como lugar de encuentro con amigos -quizá viejos clientes que se encuentran cada temporada-, en definitiva un lugar donde hacer vida social. Por distintos motivos este peculiar modo de interactuar que tenían los hoteles con la comunidad se fue perdiendo, tendiendo a globalizarse.

\section{Punta del Este: la aldea austral}

Punta del Este siempre concitó la atención de los argentinos, especialmente de los porteños. Mar del Plata, el principal balneario argentino, surge en 1874 como proyecto productivo, pero con la llegada del ferrocarril, tomó impulso como balneario marítimo. Mar del Plata se diseñó a la francesa, tomando Biarritz como paradigma. Sin embargo el balneario no contaba con bondades naturales. Según un informe técnico de 1924 Mar del Plata poco ha sido 


\section{ID_INVESTIGACIONES}

favorecido por la naturaleza: fuera de las dos lomas, por lo que su embellecimiento ha de ser siempre todo artificial...De los edificios en la costa y sobre el mismo mar, no he encontrado nada parecido en Europa, porque no son permitidas las edificaciones sobre el mar, pues es la costa la que ellos aprovechan para su mas grande embellecimiento. (Bruno, 2005, p.37)

\section{Punta del Este: La ciudad-península}

Punta del Este es una ciudad-península ya que tiene su origen en un territorio cercado por el mar en buena porción de su perímetro. El agua lo contiene y lo limita. Las penínsulas son singularidades geográficas asociadas a cualidades perceptivas que el hombre contemporáneo anhela: observar el horizonte, sentir el viento y escuchar el mar, disfrutar de un paisaje de texturas y colores variados en permanente movimiento. Aunque la península puede ser un lugar particularmente inclemente, ya en la época colonial era sitio apetecido por razones estratégico-defensivas: permitía divisar y mantener a raya al enemigo y a la vez contar con bahías o puertos naturales en sus adyacencias. No es casual que nuestras primeras ciudades coloniales, Colonia del Sacramento (1680) y Montevideo (1724), se fundaran en penínsulas.

En el Estudio Regional para Punta del Este de 1940, el arquitecto uruguayo Julio Vilamajó, ponía en valor las cualidades naturales de esta península, resaltando el aire, la costa, el mar y las sierras de la región que la conforman. La península, sin embargo, presentaba un problema: su acotada superficie limitaba su expansión. El proceso de crecimiento de Punta del Este es elocuente en este sentido: la localidad, cuyo trazado en damero remonta a fines del siglo XIX (1889), creció poco a poco, se extendió más allá de la península y terminó fundiéndose con la ciudad de Maldonado.

Vilamajó advierte de los riesgos asociados a una expansión descontrolada que, ya por entonces, observaba.
La Península de Punta del Este, casi isla, fracción de tierra rodeada por el mar y apenas apoyada en otro mar pero de arena, es la lengua rocosa que, en nuestra costa, más penetra en el agua: esto le da condiciones climatéricas y paisajísticas que no poseen otros lugares.

Su característica de excepción, de lugar único, distinto a la regla, le acuerdan la jerarquía necesaria para presidir un conjunto regional. Desde lo lejano de ambas playas se divisa esta porción de tierra que penetra francamente en el mar, puntos de vista que sería bueno exaltar".

"Apreciamos un crecimiento rápido y prodigioso y ese sentir nos sobrecoge, nos hace temer un futuro anárquico, tememos se pierdan los hilos que guian su equilibrio, tememos que el ambiente que hoy tiene una armonia tan sugestiva se transforme en un conjunto sin interés y que este rincón que hoy nos enamora pierda su encanto.

Fuente: Vilamajó, J.: Estudio Regional para Punta del Este en Lucchini, A. 1970, p.175 
Punta del Este está enmarcado por una geografía que le otorga singularidad: la costa marítima al Sur, la Laguna del Sauce y la Laguna del Diario al Oeste, el Arroyo Maldonado al Este. Todos ellos constituyen ecosistemas vulnerables que están en riesgo debido a los efectos negativos de la antropización. La Laguna del Sauce, fuente de agua potable para Punta del Este, Maldonado, San Carlos y otras localidades como Piriápolis y Pan de Azúcar, está sometida a los fuertes impactos generados por la presencia del aeropuerto, la forestación masiva, la ganadería intensiva en la cuenca y la urbanización inapropiada, lo que provoca la contaminación del agua de la laguna. Otro tanto sucede con el arroyo Maldonado y su humedal en la cuenca baja, ocupado en su borde tanto con viviendas con carencias críticas en algunos sectores, como por edificios suntuosos construidos por la vía de la excepción en otros.

La visita a Punta del Este del Ché Guevara en 1961, las tertulias culturales en la Azotea del político y escritor Eduardo Víctor Haedo, o el enamoramiento que el poeta y cantautor brasileño Vinicius de Moraes experimentó en el Este ya son parte de las anécdotas que identifican a nuestro principal balneario, otorgándole un espesor cultural diferencial. También dio acogida a exiliados artistas españoles que huían del franquismo, como Margarita Xirgu y Rafael Alberti, quien encontró allí un lugar especial que lo invitaba a crear.

\section{DEL BALNEARIO AL COUNTRY: TENDENCIAS EMERGENTES}

El club de campo -o country- es una forma de ocupación territorial residencial que se caracteriza por ser un espacio privado en su totalidad incluyendo sus vías de circulación y otros espacios abiertos, de uso exclusivo de sus propietarios o autorizados, que se presenta como alternativa a los espacios urbanos tradicionales. Su uso está extendido en el suburbio americano y con

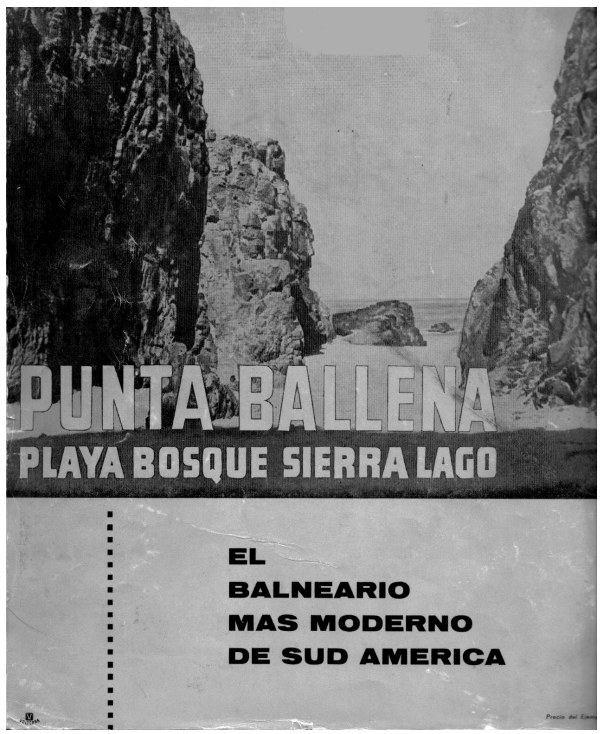

Publicidad en la Revista "Maldonado en su Bicentenario", Intendencia de Maldonado 1957 


\section{ID_INVESTIGACIONES}

gran intensidad en América Latina. San Pablo, Brasil, fue de los primeros lugares en América Latina en experimentar con este tipo de emprendimiento, con la urbanización privada Alphaville, creada en 1974 a unos 30 kilómetros del centro. El emprendimiento fue todo un éxito inmobiliario, y el modelo se expandió por todas las ciudades grandes e intermedias de Brasil. Actualmente Alphaville cuenta con 50.000 habitantes y 12.000 viviendas, además de todo tipo de servicios complementarios incluido un parque industrial no contaminante en su interior (Cymbalista, 2007).

Posteriormente, en los noventa esta modalidad llegó a Buenos Aires con el nacimiento de los countries, símbolo de renuncia de las élites al espacio público porteño.

Una serie de motivos pueden explicar el desarrollo de esta nueva manera de ocupación territorial. La ineficacia del Estado por resolver los servicios básicos

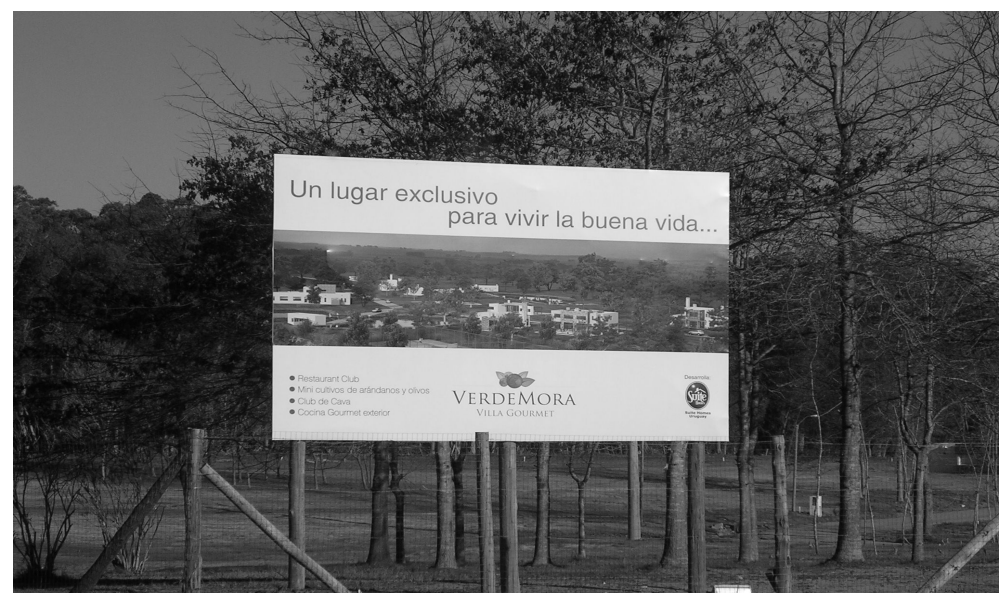

Promoción de distintos enclaves cerrados para el turismo de élite en las cercanías de Punta del Este 


\section{ID_INVESTIGACIONES}

colectivos, seguridad, constituyéndose en un verdadero mundo aparte regido por el derecho privado. Incluso algunos estados lo ven positivamente, ya que implica menos gasto público. Desde el punto de vista socio-territorial, uno de los problemas detectados es la total ausencia de espacios públicos en la trama interior de estos barrios, tales como calles y plazas, lo que lo diferencia del fraccionamiento balneario regido por la Ley de Centros Poblados (1946), que exige liberar al uso público un porcentaje del área para ese fin colectivo. Pero en general la mayor crítica al club de campo es la conformación de un gueto de exclusión que hace más tangible aún la distancia entre ricos y pobres (Bauman, 2009).

Desde el punto de vista cultural, el club de campo tiene pocos relatos que contar. No tiene una historia ni personajes que alimenten su identidad, son emprendimientos inmobiliarios que se parecen mucho unos a otros. Al llegar, accesos custodiados, y dentro, parques temáticos que simulan un barrio idílico en aparente armonía, como un suburbio norteamericano de entreguerras. Algunos aspectos de la vida en los countries de Latinoamérica, con su violencia latente y sus desavenencias, han sido registrados en filmes tales como Las viudas de los jueves (Argentina, 2009), o La Zona (México, 2007).

En Uruguay el Club Laguna Blanca, cercano a Punta del Este, resulta ser el primer emprendimiento de este tipo, realizado en el año 1990 y que hoy alcanza tan solo una ocupación del $40 \%$. Los condominios cerrados también se empiezan a promocionar a mediados de los noventa en Canelones con población permanente de la metrópolis montevideana, en torno al camino de los Horneros, pero estos han tenido un discreto desarrollo. En Colonia otro tanto, con una clientela casi exclusivamente porteña.

Los clubes de campo que hemos analizado son los destinados al consumo del tiempo libre, de una cualidad diferente al que se usa para vivir todo el año. Dicho de otro modo, el que aparece como alternativa al balneario. Resulta 


\section{ID_INVESTIGACIONES}

peculiar que en Uruguay, el primer fraccionamiento de este tipo surgió con ese fin. El club de campo comparte con el balneario el hecho de ser objeto de campañas de marketing muy específicas a la hora del loteo, donde luego la venta de unos pocos predios ya parece justificar el negocio inmobiliario, y se abre inmediatamente otra oferta sin haberse consolidado la anterior en términos de ocupación. El polémico emprendimiento Las Garzas de 240 hectáreas ubicado en Rocha es ilustrativo al respecto. El desarrollador que lo impulsa se manifiesta satisfecho con la venta de tan solo 120 lotes de los 470 con que consta el exclusivo resort. El insostenible consumo de suelo que provoca este tipo de desarrollo es acuciante: Mientras que el balneario Punta del Este y aledaños (San Rafael, Pinares) se desarrolla en 1953 hectáreas. los clubes de campo en el entorno del balneario ocupan unas 3500 hectáreas. (Acuña et al., 2010).

Respecto a la mutación del gusto del balneario al country, se puede invocar nuevamente, como a principios del siglo XIX, un cambio en la sensibilidad y formas de vida de sectores de mayores ingresos, quienes una vez más buscan alejarse de la ciudad. Temas complementarios como exclusividad, seguridad y vínculos entre iguales, imprescindibles para grupos de élite, también explican el fenómeno.

\section{SÍNTESIS}

Se ha querido abordar la temática del balneario uruguayo desde diversas miradas complementarias. Es una aproximación a distintas escalas al tema del paisaje cultural, en el entendido de que el mismo es absolutamente transescalar. 
Aires entre otras, explica el proceso de ocupación territorial de la costa uruguaya a través de una sucesión de balnearios y pueblos hilados por la infraestructura vial y marítima. Se ponen en consideración similitudes y diferencias de una y otra orilla, una arbolada, la otra descampada, según la mirada de Borges. Seguidamente se reconoce la escala regional o de la Costa Sur del Uruguay, explorando el territorio como soporte de diversos modelos espaciales, a veces inconexos e incompletos. Finalmente la escala urbana, indagando en las diversas formalizaciones y emplazamientos de los balnearios, en sus infraestructuras, equipamientos, actividades, personajes e imaginarios creados en torno al mismo.

Se procura desvelar el proyecto territorial costero y su forma, implícito en el proceso de conformación de los balnearios. Como herederos de un territorio a proyectar, se exploran las lógicas y políticas que se trazaron en él. En esa dirección se revisan los intentos planificadores desde el Estado a través de normativas como la Ley de Centros Poblados, el Código de Aguas o la más reciente Ley de Ordenamiento Territorial. Ante la avanzada a comienzos del siglo XX de la iniciativa privada a través de fraccionamientos y forestación masiva entre otros, se impulsan los intentos planificadores desde el Estado mediante políticas públicas y la implementación de un marco normativo para ordenar el territorio. Nunca hubo un gran proyecto abarcador de toda la costa, más allá del Parkway Atlántico de Cravotto, sino que diversas políticas sectoriales fueron dejando su huella, muchas veces desencontradas o no concluidas. Se cruzan miradas y sensibilidades de origen diverso que fueron construyendo el paisaje costero y del balneario. Más allá de las transformaciones técnicas del territorio, impulsadas por ingenieros $y$ arquitectos, el discurso político colaboró a construir el paisaje costero que conocemos hoy, conjuntamente con las recomendaciones higiénicas del discurso médico dominante en la sociedad del 1900.

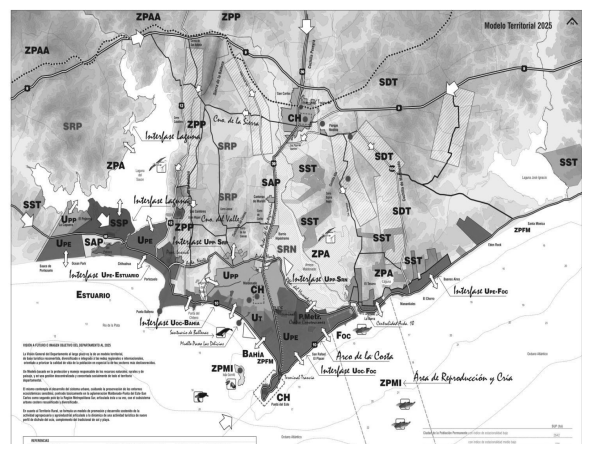

Maldonado-San Carlos-Punta del Este. La ciudad del tiempo libre y la de la población permanente. Fuente: Plan Local para la Aglomeración Central, ITU, 2010 


\section{ID_INVESTIGACIONES}

En cuanto a la génesis del balneario, se explica su nacimiento como descompresión y válvula de escape de la vida asfixiante de la ciudad. La dimensión del balneario uruguayo no se explica únicamente como contracara de la metrópolis montevideana y otras ciudades uruguayas, sino que involucra a la ciudad de Buenos Aires, a solo 50 kilómetros de la costa de Colonia. En lo que refiere a la promoción del balneario, se indaga en las formas de representación gráfica del territorio costero. No solamente se revisan los planos técnicos sino también la folletería y cartelería de promoción turística e inmobiliaria. Las políticas públicas a partir de 1930 impulsaron el turismo como actividad económica alternativa a la tradicional uruguaya. En ese marco, en 1935 se crea la Dirección Nacional de Turismo el cual juega un rol importante de difusión nacional e internacional de lugares turísticos, entre ellos la Costa y los balnearios.

El balneario constituye un paisaje cultural bien específico caracterizado por ser un territorio urbano adyacente al mar con población intermitente. Pero esta condición, si bien necesaria, no es suficiente para definirlo. El balneario está asociado a la eventualidad de lo estacional, a los flujos signados por las mareas de las temporadas. Está asociado a la actividad turístico-recreativa que suele realizarse en vacaciones y a los equipamientos necesarios para que ello suceda.

Se desvelan sus formas y trazados, así como su arquitectura y equipamiento. El balneario ha sido lugar de ensayo de expresiones de la modernidad, en tanto territorio virgen: desde trazados urbanísticos como el de Bonet en Punta Ballena, o Gómez Gavazzo en La Paloma, a arquitecturas Stream Line como el Hotel de Atlántida o de La Floresta. Se reconocen sus espacios públicos como lugar de encuentro y celebración de eventos por excelencia, principalmente la playa y la rambla. Se identifican personajes históricos ligados a su territorio y que forman parte del espesor cultural del sitio. Individuo y territorio se hacen allí 


\section{ID_INVESTIGACIONES}

uno. Complementariamente, se explora la mirada perceptiva desde las letras y las artes, profundizando así en el conocimiento del espíritu del lugar. La puesta en valor de la cultura e identidad de los balnearios resulta fundamental para que continúen siendo entornos vitales.

Finalmente, como contracara al balneario, se abre a debate el tema de los clubes de campo costeros, una nueva modalidad de habitar el tiempo libre en Uruguay, que comienza a desarrollarse en la década de 1990.

\section{BIBLIOGRAFIA}

ACUÑA, C., DE SOUZA, L., GADINO, I., LEICHT. E., MUSSO, C., VAINER, D., VARELA, A. (2010). Plan Local para la Aglomeración Central de Maldonado-San Carlos-Punta del Este. Montevideo, ITU, Facultad de Arquitectura, Universidad de la República.

ARAUJO, O. (1900). Diccionario Geográfico del Uruguay. Montevideo, Imprenta Artística de Dornaleche y Reyes.

BARRÁN; J.P. (1995). Poder médico y sociedad en el Uruguay del 900. Montevideo, EBO.

BAUMAN, Z. (2009). “Un mundo nuevo y cruel”, Ñ Revista de Cultura Clarín, Buenos Aires, 18 julio.

BORTHAGARAY, J.M. (ed.). El Río de la Plata como Territorio, FADU, UBA-FURBAN, Buenos Aires, Ediciones Infinito.

BRUNO, P. (2005). "Hacia la conformación de la ribera marítima bonaerense como territorio del turismo", Revista Registros Año No.3, Buenos Aires, Diciembre

CYMBALISTA, R. (2007). "Barrios cerrados. La transformación de las relaciones entre la esfera pública y la privada de la ciudad de Brasil", Revista Humboldt 147 año 49, (p. 2223).

GARCÍA MIRANDA, R. y RUSSI, M. (1995). "La superación de la ortodoxia. El urbanismo de Mauricio Cravotto" en Gaeta, J. (ed.). Mauricio Cravotto 1893-1962. Montevideo, Editorial Dos Puntos. 
ID_INVESTIGACIONES

LUCCHINI, A. (1970). Julio Vilamajó: Su Arquitectura. Montevideo, Universidad de la República, 1970. (p. 175-179).

LEICHT, E. (2005): "Hoteles y albergues: Indicadores de un posible turismo sustentable en microrregiones y pequeñas localidades" en OLIVERA et al. Promoción De Políticas Micro Regionales y Locales para un Turismo Ambientalmente Sustentable. UdelaR. Montevideo. Multicopiado en $\mathrm{CD}$

SABATÉ, J. (2004). Paisajes culturales. El patrimonio como recurso básico para un nuevo modelo de desarrollo. Revista Urban no. 9, Madrid

SPRECHMANN, T. et al. (2006) La Ciudad Celeste: un nuevo territorio para el Uruguay del siglo XXI. Montevideo, Facultad de Arquitectura, Universidad de la República, Fundación Colonia del Sacramento.

VIANA, I. (1995). Vigencia de una Propuesta de Ordenamiento territorial. Comentarios a "la aldea feliz" y otros textos en Gaeta, J. (ed.). Mauricio Cravotto 1893-1962. Montevideo, Editorial Dos Puntos. 
ID_ I N VESTIGACIONES

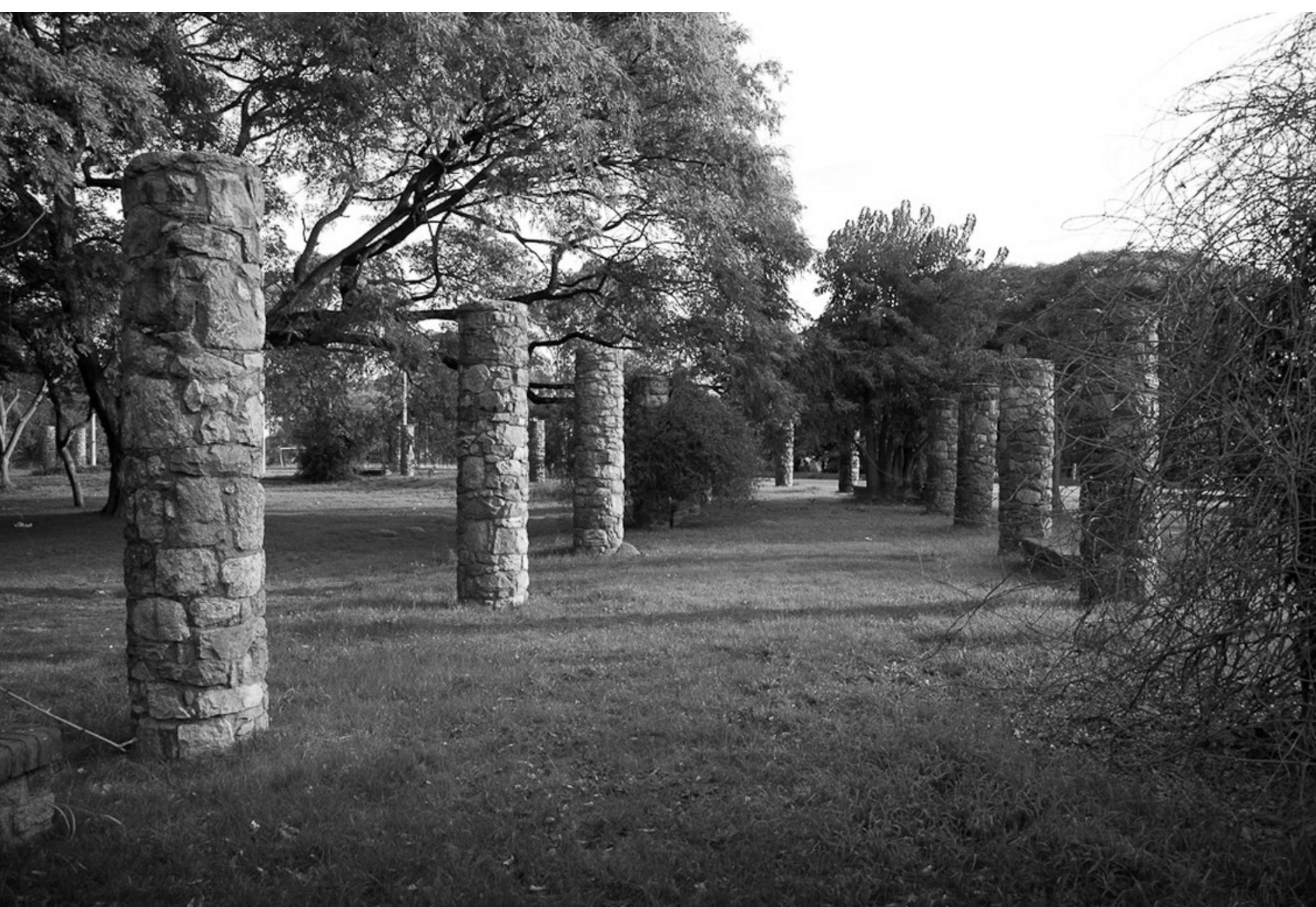

Santiago Vázquez. Fuente: foto cedida por el Servicio de Medios Audiovisuales Facultad de Arquitectura, autora Tano Marcovechio 